Japan. J. Med. Sci. Biol., 2O, 73-90, 1967

\title{
DETECTION OF HOST-ORIGINATED ACID PHOSPHATASE ON THE SURFACE OF "IN VIVO GROWN TUBERCLE BACILLI"
}

\author{
KOOMI KANAI \\ Department of Tuberculosis, National Institute of Health, Tokyo
}

(Received: October 19th, 1966)

\begin{abstract}
SUMMARY : 1. Acid phosphatase activity of the mouse lungs was elevated in response to tuberculous infection. This elevation was accelerated when the mice had been immunized with BCG.

2. "In vivo grown tubercle bacilli" (H37RvL) were separated and purified mechanically from the lungs of moribund mice which had been infected intravenously with $1 \mathrm{mg}$ of H37Rv grown on Sauton medium.

3. The $\mathrm{pH}$ activity curve of acid phosphatase of H37RvL was different from that of Sauton H37Rv, taking the pattern similar to the lung tissue.

4. Several evidences were presented to indicate that this enzyme activity of H37RvL was due to the presence of host-originated acid phosphatase bound on the surface of the bacilli.

5. In addition, it was admitted that acid phosphatase activity peculiar to Sauton H37Rv bacilli was lost or masked during their stay in the mouse lungs.

6. The intensity of acid phosphatase activity of $\mathrm{H} 37 \mathrm{RvL}$ was not affected essentially by treatment with trypsin or Triton X-100, but was completely abolished by $\mathrm{NaOH}(4 \%)$ treatment without loss of bacillary viability.

7. After incubation at $37 \mathrm{C}$ with lung tissue extract or "lysosomal fraction", Sauton H37Rv bacilli acquired totally or partially the same pattern of acid phosphatase activity as H37RvL.

8. The enzyme activity of H37RvL was interpreted as the result of lysosomeparasite interaction within phagocytes, and discussion is made referring to the recent informations concerning phagocytosis.
\end{abstract}

\section{INTRODUCTION}

In recent years, morphological and biochemical aspects of phagecytosis have been extensively studied by many workers under the current progress of methodology, as reviewed by Hirsch (1965). Particularly, the use of phase-contrast cinematography (Hirsch, 1962), electronmicroscopy (Lockwocd and Allison, 1963), and histcchemistry (Horn, Spicer and Wetzel, 1964) have demonstrated convincing evidences to support the membrane-fusion mechanism for degranulation and to indicate the discharge of granule (lysosome) contents into phagocytic vacuole within which ingested bacteria are located. It is undeniable that most bacteria will be killed or destroyed rapidly by such biological process in phagocytosis (Rowley, 1962). Some intracellular parasites can, however, multiply or survive within macrophages for a prolonged period of time, the tubercle bacillus being the representative of such kinds. In this case, it will be possible that the bacilli are bound with lysosomal components inside of phagocytic vacuole, and 
persist, being modified by, or resisting, the destructive effect of the components. In fact, Merckx, Brown, and Karlson (1964) described by an electronmicroscopic study the particular structure ( $\mathrm{X}$ body) in the tuberculous mouse lungs, which they explained as the result of interaction between lysosomes and tubercle bacilli. These informations led the present author to an attempt to detect lysosomal enzyme (acid phosphatase representatively) on the surface of "in vivo grown tubercle bacilli", and then to some model in vitro experiments regarding the interaction between tubercle bacilli and "lysosomal fraction".

\section{MATERIALS AND METHODS}

Experimental animals: Mice were used throughout the present study. They were of the commercially available dd strain, male, and weighing $20 \mathrm{~g}$ on the average. They were housed, 10 per box, on wood shavings in metal boxes with wire grid tops, and were fed with pellet diets and water.

Microorganisms: M. tuberculosis (H37Rv) and M. boris var. BCG were the microorganisms employed. They were maintained on Sauton synthetic liquid medium by subculture with 2 week intervals. Bacillary suspensions for vaccination, challenge infection, and in vitro experiments were prepared from pellicle growth on the medium. The growth was harvested on a funnel and then dried by being pressed between layered folds of absorbent filter paper. A weighed portion of thus prepared bacillary mass was put into a round flask of $300 \mathrm{ml}$ capacity containing 60 beads. A finely dispersed bacillary suspension was prepared by rotating manually the flask with occasional addition of distilled water as suspending medium. The amount of water was adjusted so that desired concentrations ( $\mathrm{mg}$ per $\mathrm{ml}$ ) of the bacilli might be obtained. The above procedure was followed using chilled materials and equipments to prevent bacillary agglutination.

Methods of raccination and infection: Whereas BCG-vaccination was conducted using intraperitoneal route of injection, infection with $\mathrm{H} 37 \mathrm{Rv}$ tubercle bacilli was conducted intravenously at the tail vein throughout the present study.

Enumeration of viable units for bacillary suspension: Enumeration of viable units of bacillary suspensions for in vivo and in vitro experiments was made by serial ten-fold dilutions of the original with distilled water, and by subsequent inoculation of $0.1 \mathrm{ml}$ of selected dilutions onto glycerol egg slants of the Ogawa type. For colony counting, incubation for 3 weeks at $37 \mathrm{C}$ was satisfactory.

Enumeration of riable units of infected lungs: Mice were sacrificed by cervical dislocation to remove aseptically the lungs. They were weighed and placed into a mortar or a glass-homogenizer to prepare a $1: 10$ diluted homogenate using $0.5 \% \mathrm{NaOH}$ solution. When required, two or three serial ten-fold dilutions were prepared from the original homogenate in distilled water. Each dilution was inoculated on 3 slants of glycerol egg medium in the amount of $0.1 \mathrm{ml}$. The numbers of colonies obtained after inoculation at $37 \mathrm{C}$ for 3 weeks allowed calculation of the numbers of viable units present in the tissue.

Separation of "in viro grown tubercle bacilli" from infected mouse lungs: The method of separation of "in vivo grown tubercle bacilli" (H37RvL) from the lungs of infected mice was essentially the same as that of Artman and Bekierkunst (1961) which was a modification of the original method of Segal and Bloch (1956). However, slight modifications were further considered in the present investigation. The lungs were 
obtained from moribund mice infected intravenously with $1 \mathrm{mg}$ of H37Rv, usually 2 to 3 weeks after infection. During this period, the lungs increased in the volume and weight ( 5 to 6 times) and the bacilli multiplied up to ten-thousand times in viable units (Kanai, Wiegeshaus, and Smith, 1965). The lungs were stored at $-20 \mathrm{C}$ until an enough amount became available for separation procedure of H37RvL.

The lungs were sliced as finely as possible, and homogenized first in a mortar and then in a Waring blendor using distilled water as medium (usually $4 \mathrm{ml}$ for the lungs of one mouse), and passed through 3 sheets of gauze. The filtrate was centrifuged at 2,000 rpm for 20 minutes. The sediment comprising heavy tissue debris and tubercle bacilli was resuspended in distilled water to the original volume and centrifugation was repeated in the same condition as before. The sediment was again resuspended to the original volume and centrifuged at $1,000 \mathrm{rpm}$ for 5 minutes. This time, the supernatant was preserved and the sediment was discarded. The supernatant was then centrifuged at 2,000 rpm for 15 minutes. The resulting sediment was resuspended in $1 \mathrm{M} \mathrm{NaCl}$ solution and incubated at $37 \mathrm{C}$ overnight to dissolve contaminating nuclear fragments. The so treated suspension was centrifuged at 3,000 rpm for 10 minutes. The pellet was washed once with $1 \mathrm{M} \mathrm{NaCl}$, and then three times with distilled water by centrifugation (Table 2). The material obtained in this way is usually a collection of acid-fast bacilli (Fig. 7) having no significant amount of blue-stained tissue debris. However, as will be described in the section of Experimental Results, further purification was possible by treatment with trypsin and Triton X-100 without interfering with the present experimental purpose. When the supernatant of the lung homogenate was to be used for collateral purpose, the homogenate was prepared using $0.25 \mathrm{M}$ sucrose solution instead of distilled water, and the subsequent procedure was followed in the same way as above.

Preparation of "lysosomal fraction" from mouse lungs: Normal or infected mouse lung homogenate was prepared using 4 times amount of $0.25 \mathrm{M}$ sucrose, and passed through 3 sheets of gauze. The filtrate was centrifuged at $2,000 \mathrm{rpm}$ for 20 minutes to obtaine supernatant, which was again treated at $3,000 \mathrm{rpm}$ for 30 minutes. The second supernatant was centrifuged at $15,000 \times \mathrm{g}$ for 20 minutes. The resulting pellet containing mitochondria and lysosomes was not separated further, but washed two times by centrifugation with $0.25 \mathrm{M}$ sucrose so that the final supernatant was negligible for acid phosphatase activity. The fraction obtained was referred to as "lysosomal fraction". In some cases, the supernatant of the centrifugation at $15,000 \times \mathrm{g}$ for 20 minutes was employed without further fractionation. As described later, the "lysosomal fraction" was characterized and identified by the observation that its acid phosphatase activity could be solubilized by Triton X-100.

Measurement of acid phosphatase activity: Activity was determined using $0.5 \%$ p-nitrophenyl phosphate as substrate in 0.1 acetate buffer ranging from $\mathrm{pH} 3.1$ to $\mathrm{pH}$ 6.22 , and also in maleic acic buffer at $\mathrm{pH} 6.5$. The reaction system consisted of $0.8 \mathrm{ml}$ of buffer, $0.1 \mathrm{ml}$ of substrate and $0.1 \mathrm{ml}$ of enzyme sample. The amount of p-nitrophenol released was measured by a Coleman Spectrophotometer set at $420 \mathrm{~m} \mu$ after alkalinization with $2 \mathrm{ml}$ of $0.5 \mathrm{M} \mathrm{NaOH}$. The activity was expressed as $\mu$ moles of p-nitrophenol liberated in a given time at $40 \mathrm{C}$ by a defined amount of test samples each time. When required, the assay was conducted in the environment containing $0.25 \mathrm{M}$ sucrose.

Cytochemical staining of acid phosphatase of H37RvL : A modification of Gomori's technique (1941) was employed in vitro for cytochemical staining of acid phosphatase of H37RvL. H37RvL sample purified as described before was further treated with trypsin of $200 \mu \mathrm{g}$ per $\mathrm{ml}$ of $\mathrm{M} / 15$ phosphate buffer $(\mathrm{pH} 8.0$ ) for $2 \mathrm{hr}$ at $37 \mathrm{C}$, and then 
washed two times by centrifugation at $3,000 \mathrm{rpm}$ for 20 minutes with distilled water. The final pellet was subjected to the staining. Ten $\mathrm{ml}$ of the first solution $(120 \mathrm{mg}$ of $\mathrm{Pb}\left(\mathrm{No}_{3}\right)_{2}$ in $100 \mathrm{ml}$ of $0.1 \mathrm{M}$ acetate buffer, $\mathrm{pH} \mathrm{3.5)}$ was mixed with $1 \mathrm{ml}$ of the second solution ( $3 \%$ sodium glycerophosphate solution). And, the pellet of H37RvL was resuspended in this mixed solution and incubated at $37 \mathrm{C}$ overnight. The suspension was then centrifuged at $3,000 \mathrm{rpm}$ for 10 minutes to obtain sediment. The sediment was resuspended in distilled water and washed three times by centrifugation. The resulting pellet was treated with diluted sodium sulfide, being followed by washing with distilled water three times. This preparation was ready for microscopic observation on a slide glass.

\section{EXPERIMENTAL RESULTS}

\section{Response to Tuberculous Infection of Acid Phosphatase Activity of the Lungs in Mice} Unvaccinated and Vaccinated with $B C G$.

Eighty mice were divided into 4 groups of equal 20. Two groups were vaccinated by intraperitoneal injection with $1 \mathrm{mg}$ of $\mathrm{BCG}$ and the remaining two groups were left unvaccinated. Three weeks after the vaccination, the animals of one vaccinated and one unvaccinated groups were challenged intravenously with $1 \mathrm{mg}$ of $\mathrm{H} 37 \mathrm{Rv}$ (16× $10^{6}$ viabe units) and those of the remaining two groups were infected in the same way with half the dose. Concerning the former two groups of heavier challenge infection, the vaccination effect was evaluated by prolongation of survival days of the vaccinated mice (Fig. 1). In the latter two groups, body weight, acid phosphatase activity of the lungs and lung viable counts were examined 6 times with one week intervals, starting from the day of infection. The examination was done each time sampling 3 animals at random from each group. The lungs collected from 3 animals were divided into two parts, one for enzyme assay and the other for viable counting. Measurement of the enzyme activity was done using $0.1 \mathrm{ml}$ of a $1: 100$ diluted homogenate $0.25 \mathrm{M}$ sucrose) at $\mathrm{pH} 4.8$ for 30 minutes, and expressed as the amount $(\mu \mathrm{M})$ of released p-nitrophenol by the whole lungs; $1 / 1,000$ numeration of the value being the index. Viable counts per whole lungs were determined by the already described method. These results are presented in Figs. 2, 3 and 4.

Fig. 1 indicates that intravenous infection with $1 \mathrm{mg}$ of $\mathrm{H} 37 \mathrm{Rv}$ could kill unvaccinated mice in 2 to 3 weeks and that BCG vaccination protected them from such a fatal infection. In the case of the smaller challenge size $(0.5 \mathrm{mg})$, however, the mice of both vaccinated and unvaccinated groups could survive. Therefore, the time-course observation of lung enzymatic response, body weight, and viable counts was possible comparing the two groups. Fig. 3 shows that the enzyme activity of the whole lungs was elevated to 4 to 6 folds in response to tuberculous infection after the second week, and that this elevation was accelerated by the previous vaccination with BCG as revealed by the high activity as early as in one week. It appears quite likely that this promptness of enzymatic response in the vaccinated mice is largely due to the accelerated cellular response to infection, probably the earlier and enhanced mobilization of phagocytic cells. On the other hand, Fig. 4 shows that multiplication of infecting bacilli was greatly inhibited in the vaccinated mice, being another demonstration of the protective effect of BCG vaccine. Body weight change as indicated in Fig. 2 is also a matter of interest. In the vaccinated mice, body weight decreased accompanying general malaise appearance for the first week of infection, being followed by the gradual recovery during the 


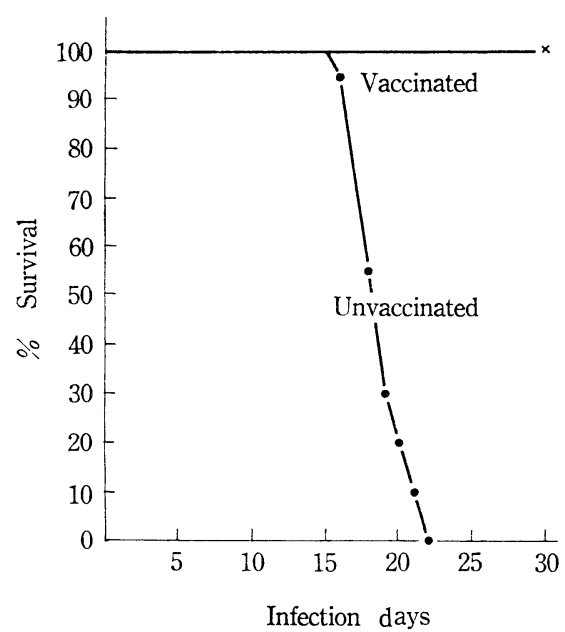

Fig. 1. Protective effect in mice of BCGvaccination against intravenus challenge with $1 \mathrm{mg}$ of H37Rv.

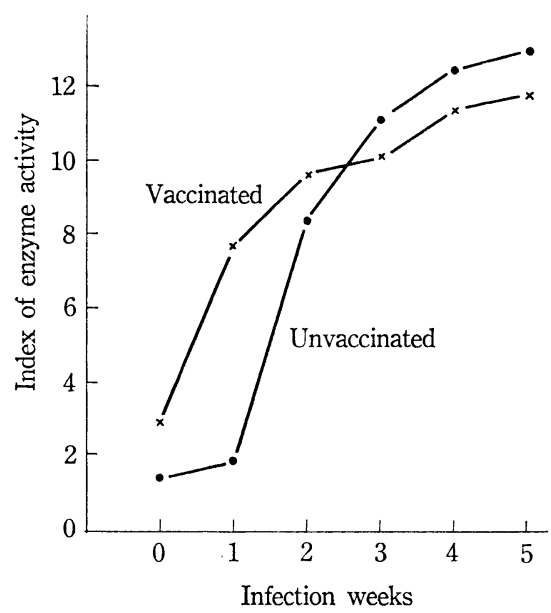

Fig. 3. Response to infection of acid phosphatase activity of the lungs in mice unvaccinated and vaccinated with $B C G$

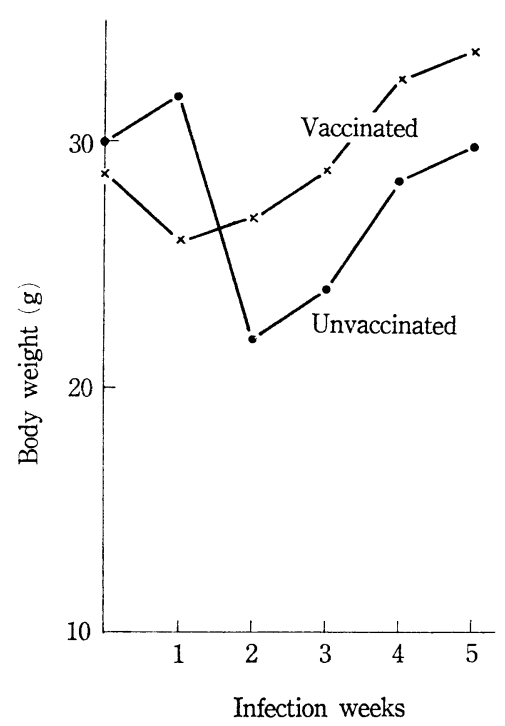

Fig. 2. Average body weight change of BCG-vaccinated and unvaccinated groups of mice after intravenous challenge with $0.5 \mathrm{mg}$ of H37Rv.

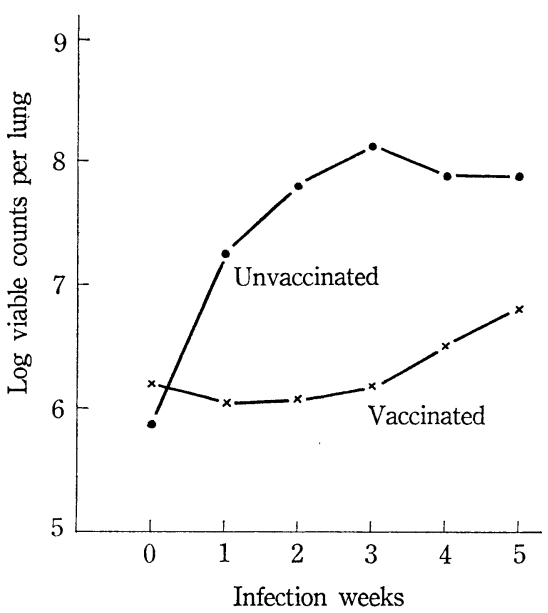

Fig. 4. Fate of the virulent tubercle bacilli $(\mathrm{H} 37 \mathrm{Rv})$ in the lungs of mice unvaccinated and vaccinated with $B C G$.

succeeding weeks. On the contrary, body weight of the unvaccinated mice increased, though not markedly, in the first week, being followed by a sudden decrease by approximately $10 \mathrm{~g}$ in the second week. Recovery ensued thereafter. These observations, together with those of the enzymatic response as shown in Fig. 3, suggest that host cell mobilization to infection can occur more promptly and proceed more rapidly in BCG vaccinated mice. Besides, the above observations of lung acid phosphatase 
response to tuberculous infection may constitute a starting point of the present investigation.

Differences in pH Activity Curce of Acid Phosphatase between H37RvL and H37Rv.

The bacilli which multiplied in the mouse lungs (H37RvL) were separated, by the procedure shown in Table 2, from the organs of moribund mice which had been infected intravenously with $1 \mathrm{mg}$ of $\mathrm{H} 37 \mathrm{Rv}$ grown on Sauton medium. The yield of $\mathrm{H} 37 \mathrm{RvL}$ was usually 4 to $6 \mathrm{mg}$ (wet weight) per lungs of one mouse. The acid phosphatase activity of $\mathrm{H} 37 \mathrm{RvL}$ and Sauton $\mathrm{H} 37 \mathrm{Rv}$ was examined at 12 different $\mathrm{pH}$ ranging from 3.1 to 6.5 . Both samples were used in an equal amount of $5 \mathrm{mg}$ and the reactions were read at 60 minutes. The results are shown in Fig. 5. The two pH activity curves are so different in shape. The curve of Sauton $\mathrm{H} 37 \mathrm{Rv}$ has a round peak between 5.6 to 4.7 , a steep slope between 5.6 to 4.7 , and finally a horizontal line between 4.7 and 3.1 due to negligible reactions. In contrast, the curve of $\mathrm{H} 37 \mathrm{RvL}$ shows an elevated plateau between 3.1 and 5.0 , a gentle slope between 5.0 and 6.2 , and finally a steep slope down to 6.5 at which the activity is extremely low. As will be described later, this curve is quite similar to that of the lung tissue itself, if not the same. Fig. 6 shws an example of time-course reading of acid phosphatase reactions at $\mathrm{pH} 3.5,5.0$ and 6.5 concerning other samples of $\mathrm{H} 37 \mathrm{Rv}, \mathrm{H} 37 \mathrm{RvL}$, and the infected mouse lungs from which H37RvL was separated. Here again, the marked contrast between H37Rv and $\mathrm{H} 37 \mathrm{RvL}$ is demonstrated in the activities at $\mathrm{pH} 3.5$ and 6.5. The reactions by the infected lung tissue are similar to those of $\mathrm{H} 37 \mathrm{RvL}$, except a much stronger reaction at $\mathrm{pH} 6.5$ in the former. This point is one of the evidences indicating that such a pattern of acid phosphatase activity of $\mathrm{H} 37 \mathrm{RvL}$ is not due to simple combination or contamination between $\mathrm{H} 37 \mathrm{Rv}$ and lung tissue fragments.

Effect of Treatment with Trypsin, $\mathrm{NaOH}$, or Triton X-10O on the Acid Phosphatase Activity of $H 37 R v L$.

A H37RvL sample was divided into 4 parts, one being left untreated as the original

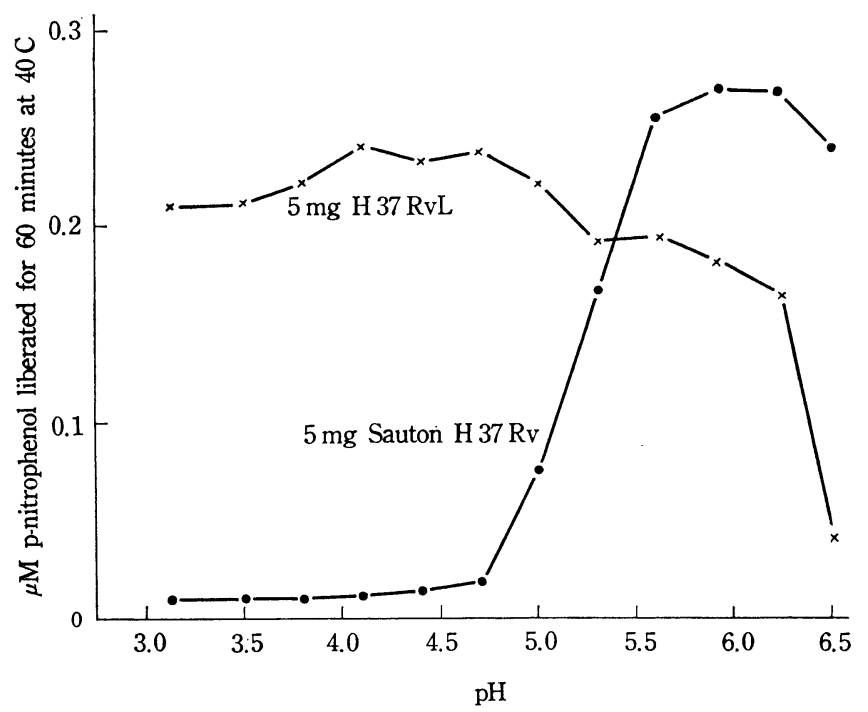

Fig. 5. Acid phosphatase activity of H37RvL in comparison with H37Rv grown on Sauton synthetic liquid medium. 

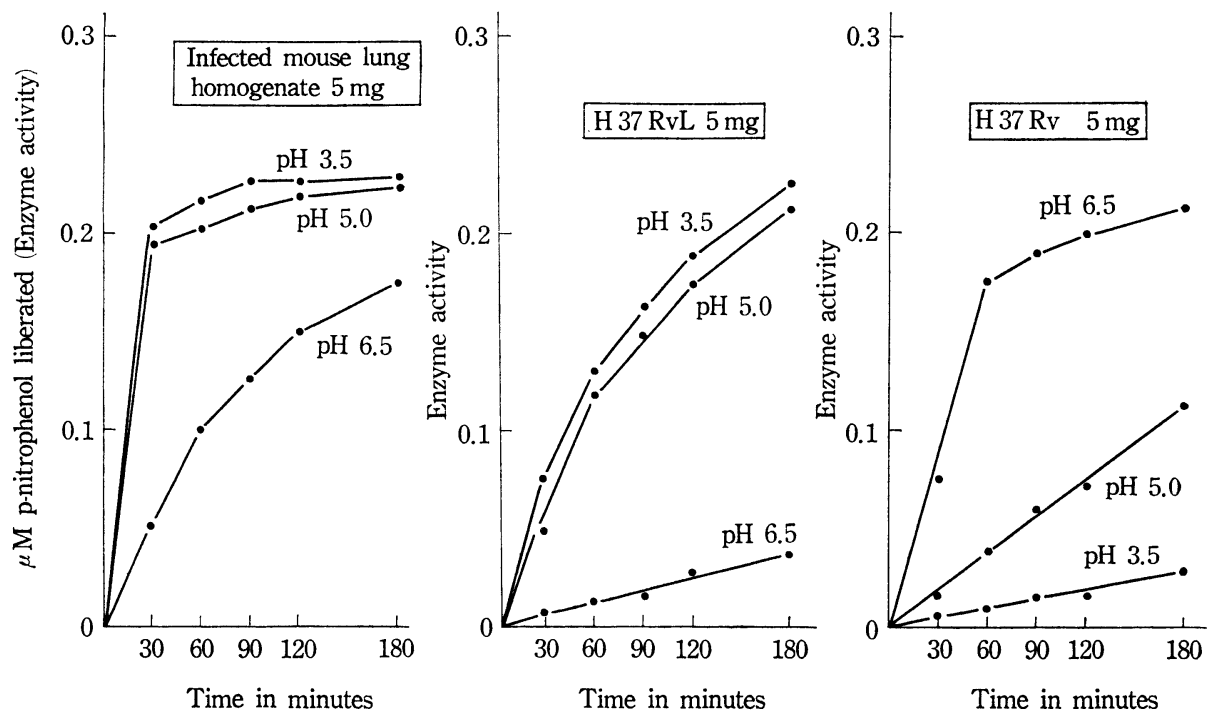

Fig. 6. Acid phosphatase activity of H37Rv, H37RvL, and infected mouse lung homogenate from which $\mathrm{H} 37 \mathrm{RvL}$ cells were separated.

and the remaining three being treated with trypsin, $\mathrm{NaOH}$, or Triton $\mathrm{X}-100$. Trypsin treatment was done in $200 \mu \mathrm{g} / \mathrm{ml}$ of $\mathrm{M} / 15$ phosphate buffer $(\mathrm{pH} 8.0)$ for $3 \mathrm{hr}$ at $37 \mathrm{C}$. $\mathrm{NaOH}$ treatment was done in a $4 \%$ solution for $1 \mathrm{hr}$ at $37 \mathrm{C}$. Triton X-100 treatment was conducted in the environment of $5 \%$ for $1 \mathrm{hr}$ at $37 \mathrm{C}$. After the treatment, each sample was washed well by centrifugation using distilled water. Then, acid phosphatase activity of the treated samples was examined at various $\mathrm{pH}$ in comparison with that of the original sample. The results are shown in Table 1. The enzyme activity was completely abolished by the $\mathrm{NaOH}$ treatment, but it remained intact after the trypsin treatment. The decrease of activity was slight in the case of the Triton X-100 treatment. Triton X-100 was used here considering its lysosome-disruting property. However, the

Table 1. Effect of the treatment with trypsin, $\mathrm{NaOH}$, and Triton $\mathrm{X}-100$ on the acid phosphatase activity of H37RvL

\begin{tabular}{|c|c|c|c|c|c|c|}
\hline & \multicolumn{6}{|c|}{$\begin{array}{l}\mu \mathrm{M} \text { p-nitrophenol liberated during } 2 \mathrm{hr} \text { incubatior } \\
(40 \mathrm{C}) \text { at below-indicated } \mathrm{pH}\end{array}$} \\
\hline & 3.5 & 4.1 & 4.7 & 5.3 & 5.9 & 6.5 \\
\hline $\begin{array}{c}\text { Untreated original } \\
\text { H37 RvL } 5 \mathrm{mg}\end{array}$ & 0.25 & 0.25 & 0.25 & 0.25 & 0.23 & 0.054 \\
\hline \multicolumn{7}{|l|}{ After treatment with } \\
\hline Trypsin & 0.25 & 0.23 & 0.23 & 0.25 & 0.20 & 0.05 \\
\hline $\mathrm{NaOH}$ & 0 & 0 & 0 & 0 & 0 & 0 \\
\hline Triton X-100 & 0.20 & 0.20 & 0.19 & 0.20 & 0.19 & 0.018 \\
\hline
\end{tabular}

Note: Trypsin treatment : $200 \mu \mathrm{g} / \mathrm{ml}$ of $\mathrm{M} / 15$ phosphate buffer $(\mathrm{pH} 8.0$ ) for $3 \mathrm{hr}$ at $37 \mathrm{C}$. $\mathrm{NaOH}$ treatment : $4 \%$ for $1 \mathrm{hr}$ at $37 \mathrm{C}$.

Triton X-100 treatment: $5 \%$ for $1 \mathrm{hr}$ at $37 \mathrm{C}$. 
slight effect as observed above might be due to its nonspecific washing property as a detergent; because the H37RvL sample had been obtained from the lung homogenate made in distilled water and not in $0.25 \mathrm{M}$ sucrose solution. Of utmost interest is the fact that $4 \% \mathrm{NaOH}$ can abolish the enzyme activity of $\mathrm{H} 37 \mathrm{RvL}$ without destroying their viability, as will be described in the succeeding paper.

Evidences to Indicate That Acid Phosphatase Activity of H37RvL Sample is not due to Contamination with Lung Tissue Fragments.

Experiment 1. An H37RvL sample was obtained by the already described procedure (Table 2) and it was an almost pure collection of acid-fast bacilli (Fig. 7). Besides, the cytoplasmic granules (lysosomes) containing acid phosphatase are considered not to be sedimented by the centrifugation gravity as employed hare. Particularly, in the case of aqueous homogenate, this is true because of probable solubilization of the enzyme. To confirm this point, an experiment was conducted to assay acid phosphatase activity of the serial precipitates, supernatants, and washings obtained during the process of H37RvL preparation (Table 3). The starting material was $50 \mathrm{~g}$ of infected lungs. As

Table 2. Mechanical isolation of " in vivo grown tubercle bacilli",

(H37RvL) from infected mouse lungs

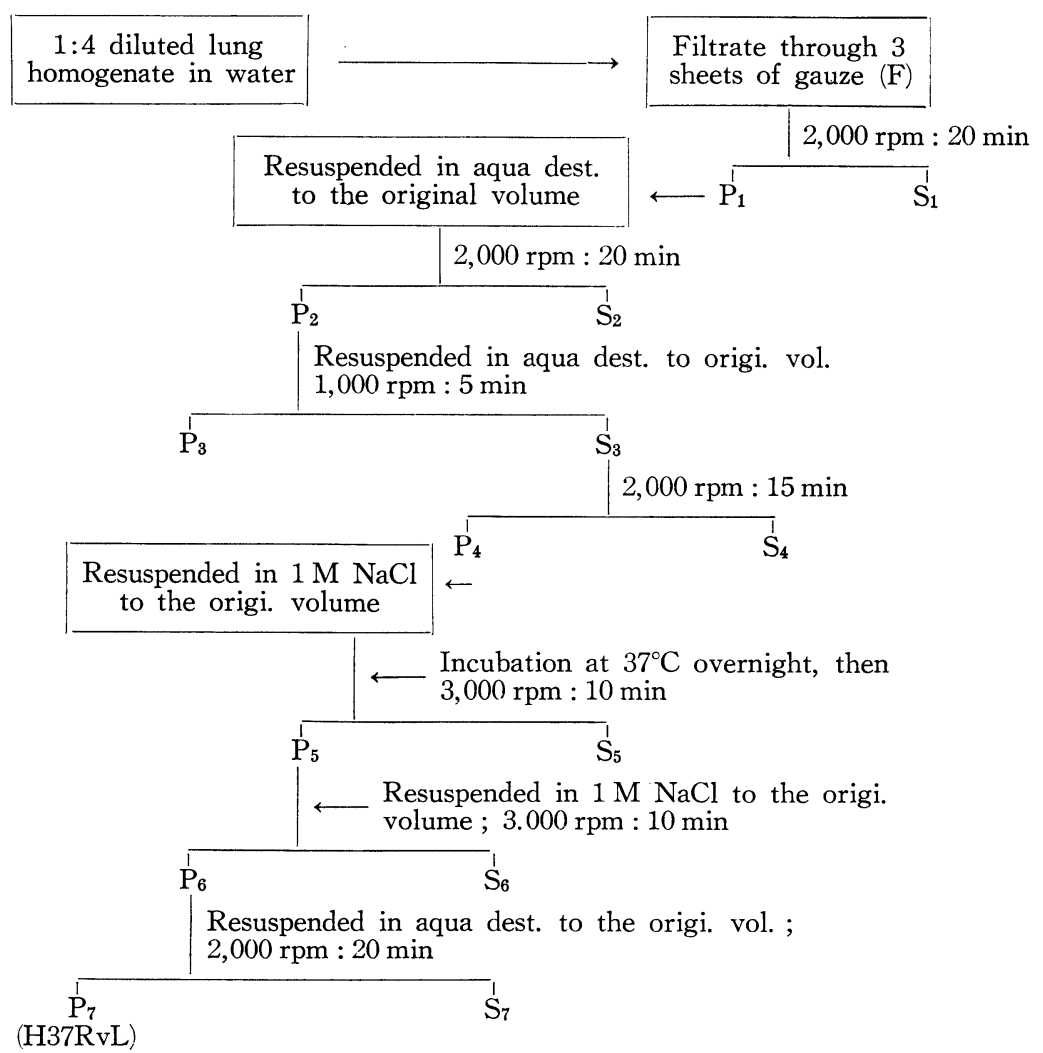

Note: Further purification was made, in some cases, using trypsin, Triton X-100, or $\mathrm{NaOH}$. When required, the starting lung homogenate was prepared using $0.25 \mathrm{M}$ sucrose instead of distilled water. 
the control, the same procedure was followed using lungs from 100 normal mice. Each precipitate was resuspended in distilled water or $1 \mathrm{M} \mathrm{NaCl}$ to the original volume of the first gauze filtrate of the lung homogenate to measure the relative enzyme activity. The results are shown in Table 3. Finally, the H37RvL sample was stained cytochemically in vitro according to a slightly modified Gomori's technique (Fig. 8). The table demonstrates that in the infected mouse lung homogenate, the major part of the enzyme activity moved to the supernatant fractions, and that the later washing lost the activity completely along with the fairly constant activity of the resulting precipitates. In the case of the normal lungs, the major part of the activity again moved to the first supernatant, but the activity was soon lost from both the washings and precipitates. The amount of the last precipitate was negligible in amount. These results clearly indicat? that acid phosphatase activity of the $\mathrm{H} 37 \mathrm{RvL}$ sample was not due to simple contamination by tissue fragments, but it was intimately associated with the bacilli themselves.

Table 3. Distribution of acid phosphatase activity in supernatants $\left(\mathrm{S}_{1}\right.$ to $\left.\mathrm{S}_{6}\right)$ and precipitates $\left(\mathrm{P}_{1}\right.$ to $\left.\mathrm{P}_{7}\right)$ obtained from lung homogenate during the procedure of isolation of " in vivo grown tubercle bacilli" shown in Table 2

\begin{tabular}{|c|c|c|c|c|c|}
\hline \multirow{2}{*}{\multicolumn{2}{|c|}{ Sample }} & \multicolumn{4}{|c|}{$\begin{array}{l}\text { Enzyme activity at } \mathrm{pH} 4.1(\mu \mathrm{M} \text { p-nitrophenol released } \\
\text { by the total amount of sample for } 1 \mathrm{hr} \text { at } 40 \mathrm{C})\end{array}$} \\
\hline & & \multicolumn{2}{|c|}{ Infected mouse lungs } & \multicolumn{2}{|c|}{ Normal mouse lungs } \\
\hline \multicolumn{2}{|c|}{$\mathrm{F}$} & & \multirow{2}{*}{420} & & \multirow{2}{*}{120} \\
\hline $\mathrm{S}_{1}$ & $P_{1}$ & & & & \\
\hline $\mathrm{S}_{2}$ & $P_{0}$ & 300 & \multirow{2}{*}{280} & 37 & 15 \\
\hline $\mathrm{S}_{3}$ & 12 & 120 & & 0 & 10 \\
\hline $\mathrm{S}_{4}$ & $P_{3}$ & 24 & 64 & 0 & 0 \\
\hline$S_{5}$ & $\mathrm{P}_{4}$ & 0 & 60 & 0 & 0 \\
\hline \multirow{3}{*}{$\mathrm{S}_{6}$} & $P_{5}$ & 0 & 58 & \multirow{3}{*}{0} & 0 \\
\hline & $P_{6}$ & & 62 & & 0 \\
\hline & $\mathrm{P}_{7}$ & & 41 & & 0 \\
\hline
\end{tabular}

Fig. 8 shows black stained particles in the microscopic field, being rod, oval or round in shape. They were usually much wider than Ziehl-Neelsen stained rods which corresponded to the inside of the cell wall structure (Yegian and Vanderlinde, 1947). Probably it means that the enzyme was present on the surface of the bacilli, and that reaction products were deposited thereon. In some cases, however, it would be possible that black-stained particles are bacilli-containing secondary lysosomes. This possibility is easily suspected from ultrastructural and cytochemical pictures of phagocytosis presented by Horn, Spicer and Wetzel (1964). In addition, it was felt that the bacilli which could be stained cytochemically might be a part of the Ziehl-Neelsen stained population of the bacilli, though double staining was not successful. The cytochemical staining at $\mathrm{pH} 3.5$ as employed here could not stain Sauton H37Rv bacilli.

Experiment 2. A model experiment was conducted regarding the enzyme activity of the mixture of Sauton H37Rv and normal lung tissue in comparison with that of H37RvL. 


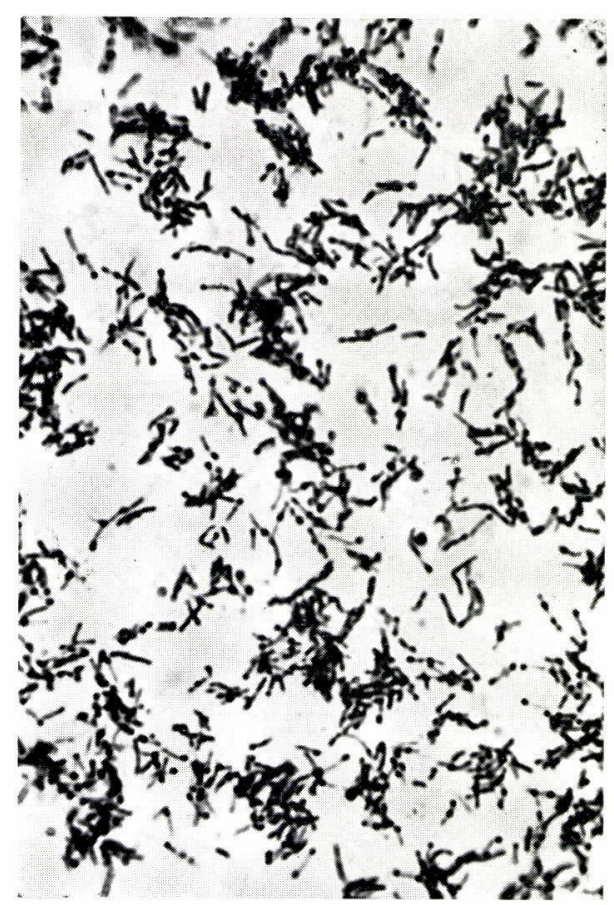

Fig. 7. A preparation of "in vivo grown tubercle baclli" (H37RvL) separated from infected mouse lungs Stained by Ziehl-Neelsen method).

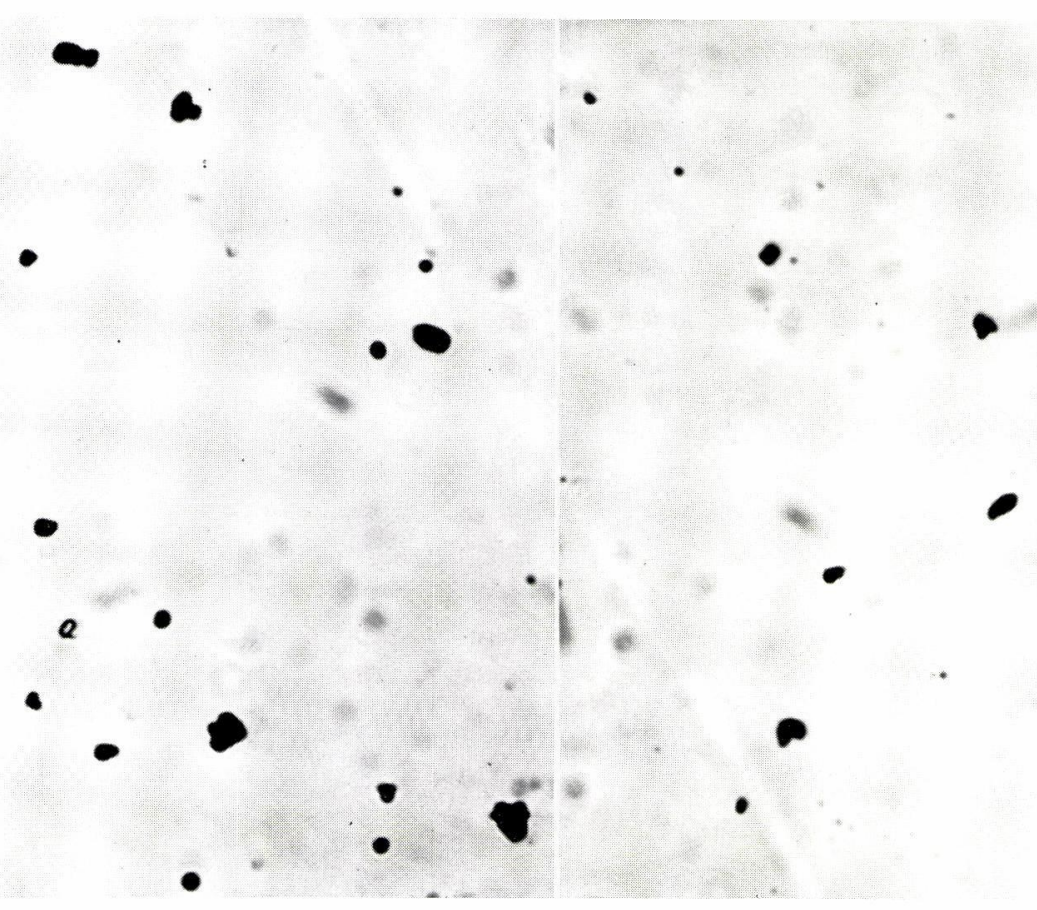

Fig. 8. Cytochemical staining of an H37RvL sample by modified Gomori's technique for acid phosphatase activity at $\mathrm{pH} 3.5$ (oil-immersion; $1,500 \mathrm{x}$ ). 
Three samples, namely $2.5 \mathrm{mg}$ of $\mathrm{H} 37 \mathrm{Rv}, 2.5 \mathrm{mg}$ of the lung homogenate, and their combination were prepared for assay of acid phosphatase activity. Their $\mathrm{pH}$ activity curves were compared with that of $5 \mathrm{mg}$ of H37RvL. The results are shown in Fig. 9. As expected before, the curve of the combined material can be explained simply as the addition of the activities of $\mathrm{H} 37 \mathrm{Rv}$ and the lung homogenate. In contrast, the curve of H37RvL can not be explained by such addition, particularly in the point that the activity was quite low at $\mathrm{pH}$ 6.5. Thus, this experimental result will serve as another evidence proving that the acid phosphatase activity of H37RvL is not due to the mixture of $\mathrm{H} 37 \mathrm{Rv}$ and the lung homogenate. Besides, as seen in this figure, the intensity of enzyme activity of $\mathrm{H} 37 \mathrm{RvL}$ was not so different from the lung homogenate if compared in a corresponding amount. This was confirmed in repeated experiments thereafter. Judging from the fact that H37RvL cells were separated and concentrated from the infected lung homogenate, the above observation appears paradoxical. The extent of concentration was usually 50 times at least when evaluated by comparative observation of the number of acid-fast stained bacilli between the starting lung homogenate and the obtained H37RvL sample. Therefore, only one interpretation may be that the hostoriginated enzyme was present attaching to the bacillary body. However, the low activity at $\mathrm{pH} 6.5$ can not be explained only by such attachment, and inhibition of the acid phosphatase activity peculiar to $\mathrm{H} 37 \mathrm{Rv}$ by some host-factor must be considered simultaneously.

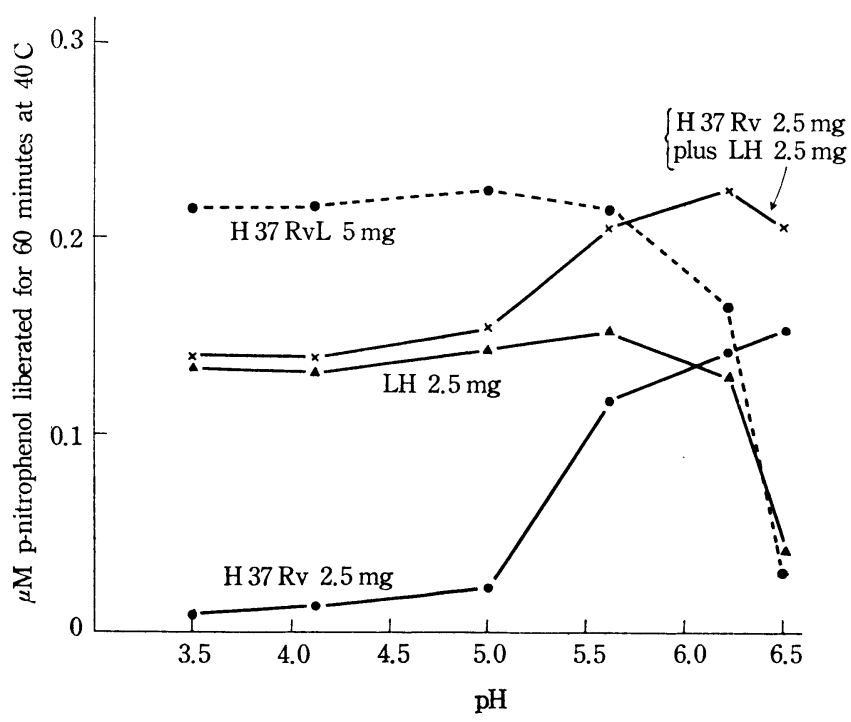

Fig. 9. Acid phosphatase activitv of the mixture of $\mathrm{H} 37 \mathrm{Rv}$ and normal mouse lung homogenate $(\mathrm{LH})$ in comparison with H37RvL.

Experiment 3. To examine a possibility that the location of acid phosphatase activity of H37RvL might be the surface structure, a crude cell wall fraction was isolated from $3.5 \mathrm{~g}$ of H37RvL sample by the procedure shown in Table 4. The enzyme activity of the fraction was examined at various $\mathrm{pH}$ comparing with the original $\mathrm{H} 37 \mathrm{RvL}$ sample. The result is shown in Table 5. Though reduced in the intensity, the pattern of the $\mathrm{pH}$ activity curve of both samples was the same. In view of the fact that acid 
Table 4. Isolation of crude cell wall fraction from H37RvL sample

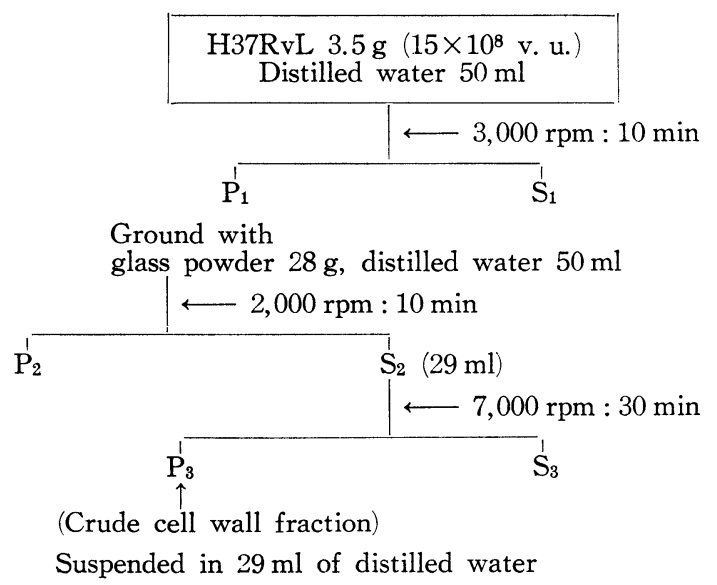

Note: $S_{1}, S_{2}$, and $S_{3}$ are supernatants, and $P_{1}, P_{2}$, and $P_{3}$ are precipitates.

Table 5. Acid phosphatase activity of crude cell wall fraction isolated from $\mathrm{H} 37 \mathrm{RvL}$

\begin{tabular}{cccccc}
\hline & \multicolumn{5}{c}{$\begin{array}{c}\text { Enzyme activity } \\
\text { for } 60\end{array}$} \\
\cline { 2 - 6 } Sample & $\begin{array}{c}(\mu \mathrm{M} \text { p-nitrophenol liberated } \\
\text { minutes at }\end{array}$ & $40 \mathrm{C})$ \\
\cline { 2 - 6 } & 4.1 & 4.4 & 5.0 & 5.6 & 6.5 \\
\hline $\begin{array}{c}\text { H37RvL } \\
\text { Crude cell wall } \\
\text { fraction }\left(\mathrm{P}_{3}\right)\end{array}$ & 0.53 & 0.45 & 0.42 & 0.39 & 0.15 \\
\hline
\end{tabular}

phosphatase activity of in vitro cultured tubercle bacilli is found only in the internal structure of the cell (Kanai, 1964) (Yamaguchi, 1966), the activity of the cell wall fraction of $\mathrm{H} 37 \mathrm{RvL}$ is most easily explained as the host-originated one.

Modification of Acid Phosphatase Activity of Sauton H37Rv by Treatment with Normal and Infected Mouse Lung Extracts.

As a preliminary model experiment which might shed some light on the nature of acid phosphatase activity of "in vivo grown tubercle bacilli", the effect of treatment with mouse lung extracts upon the enzyme activity of Sauton $\mathrm{H} 37 \mathrm{Rv}$ was examined.

The lungs obtained from 106 normal mice ( $29 \mathrm{~g}$ totally) were homogenized using $100 \mathrm{ml}$ of $0.25 \mathrm{M}$ sucrose solution. The homogenate was filtered through three sheets of gauze. The filtrate was centrifuged twice, first at $3,000 \mathrm{rpm}$ for 20 minutes and then at 7,000 rpm for 20 minutes. The final supernatant in the amount of $80 \mathrm{ml}$ was used as normal lung extract. On the other hand, infected mouse lung extract was prepared in the same way from the lungs of 68 infected animals ( $61 \mathrm{~g}$ totally) homogenized using $250 \mathrm{ml}$ of $0.25 \mathrm{M}$ sucrose solution. Eighty $\mathrm{ml}$ of the extracts was added with $\mathrm{MgSO}_{4}$ and $\mathrm{CaCl}_{2}$ to the concentration of $0.02 \mathrm{M}$, and also with $500 \mathrm{mg}$ of BCG suspended in $10 \mathrm{ml}$ of the sucrose solution. The bacilli-extract mixtures were incubated at $37 \mathrm{C}$ for $4 \mathrm{hr}$ and then left to stand in an ice-box overnight. BCG organisms were recovered by centrifugation at $3,000 \mathrm{rpm}$ for 20 minutes, and washed repeatedly using $1 \mathrm{M} \mathrm{NaCl}$ 
and distilled water. The final sediment was resuspended in distilled water in the concentration of $50 \mathrm{mg}$ per $\mathrm{ml}$. Ziehl-Neelsen staining revealed that the suspension consisted purely of acid-fast bacilli and contained no blue stained tissue components.

Acid phosphatase activity of the two BCG suspensions thus treated was examined at various $\mathrm{pH}$ in comparison with an untreated $\mathrm{BCG}$ suspension of the same concentration. Reading of reaction was made after 90 minutes' incubation at $40 \mathrm{C}$. At the same time, the enzyme activity of both lung extracts per se was also examined. The results are shown in Fig. 10. In this figure, an indication is presented that the BCG suspension treated with the infected mouse lung extract acquired the enzyme activity at $\mathrm{pH}$ range from 3.5 to 5.0 which was absent in the original BCG suspension. The activity of both lung extracts was found to be almost the same.

Fig. 11 is another example of the effect of the treatment with infected mouse lung extract upon the enzyme activity of BCG. Here again, elevation of the enzyme activity at $\mathrm{pH} 3.5$ to 5.0 was demonstrated. Therefore, the pattern of $\mathrm{pH}$ activity curve of the treated BCG suspension appears to be a combination pattern of untreated BCG and lung tissue extract.

Acid Phosphatase Activity of Sauton H37Rv Treated with "Lysosomal Fraction" Obtained from Mouse Lung Homogenate.

"Lysosomal fraction" was prepared from the lungs of 50 infected mice by the procedure described above. In analysis of an aliquot of the fraction, approximately $90 \%$ of the acid phosphatase activity of this fraction was found to be solubilized by Triton X-100 treatment. The fraction was washed twice by centrifugation using $0.25 \mathrm{M}$ sucrose. Then, $500 \mathrm{mg}$ of $\mathrm{BCG}$ organisms and the fraction was mixed to make a suspension in $30 \mathrm{ml}$ of $0.25 \mathrm{M}$ sucrose solution. The mixture was incubated at $37 \mathrm{C}$ overnight in the presence of a few drops of toluene. Then, the mixture was centrifuged at 2,000 rpm for 10 minutes. The sediment was washed repeatedly with $0.25 \mathrm{M}$ sucrose

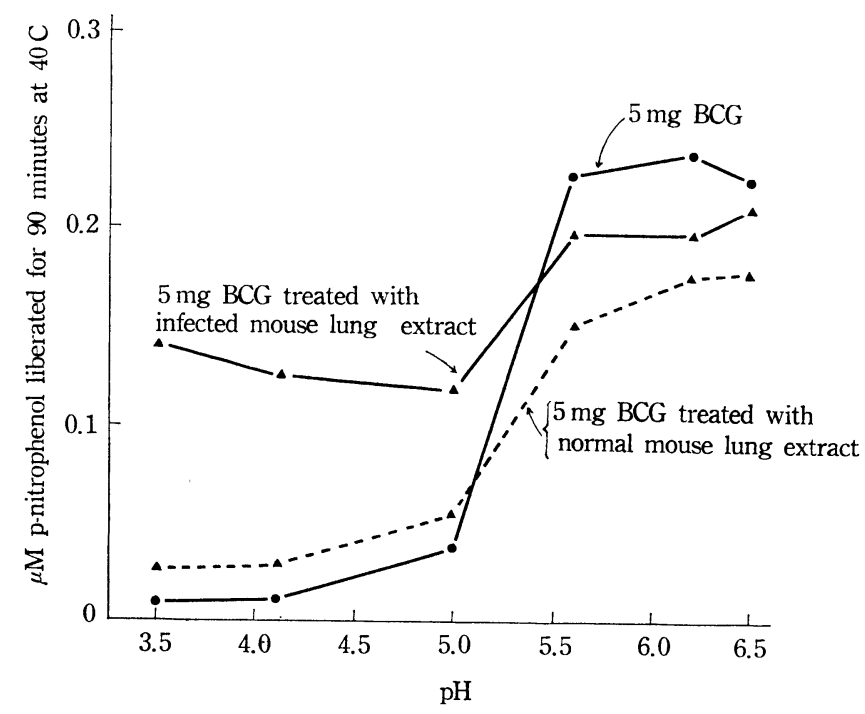

Fig. 10. Acid phosphatase activity of BCG treated with normal or infected mouse lung extract, in comparison with original BCG grown on Sauton medium. 


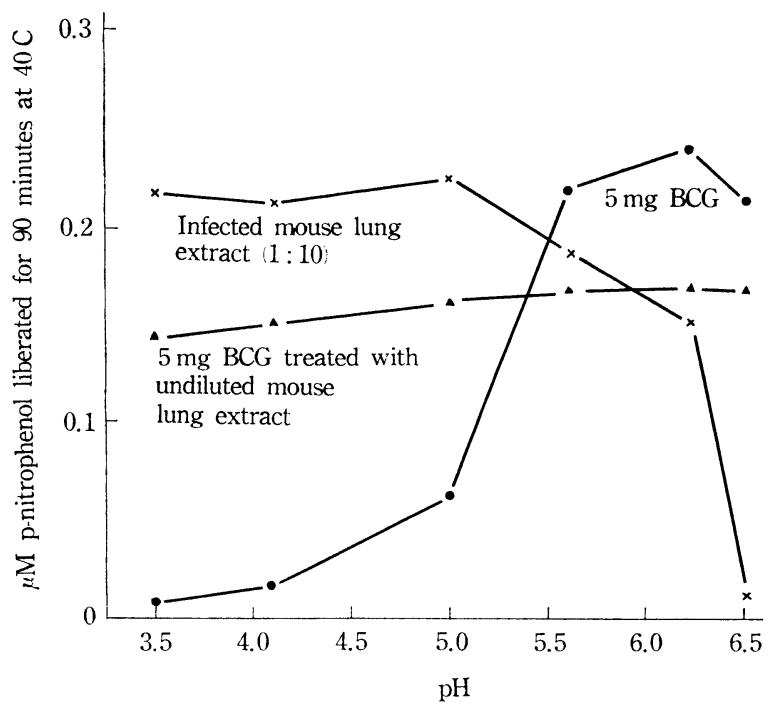

Fig. 11. Acid phosphatase activity of BCG treated with infected mouse lung extract, in comparison with original BCG grown on Sauton medium.

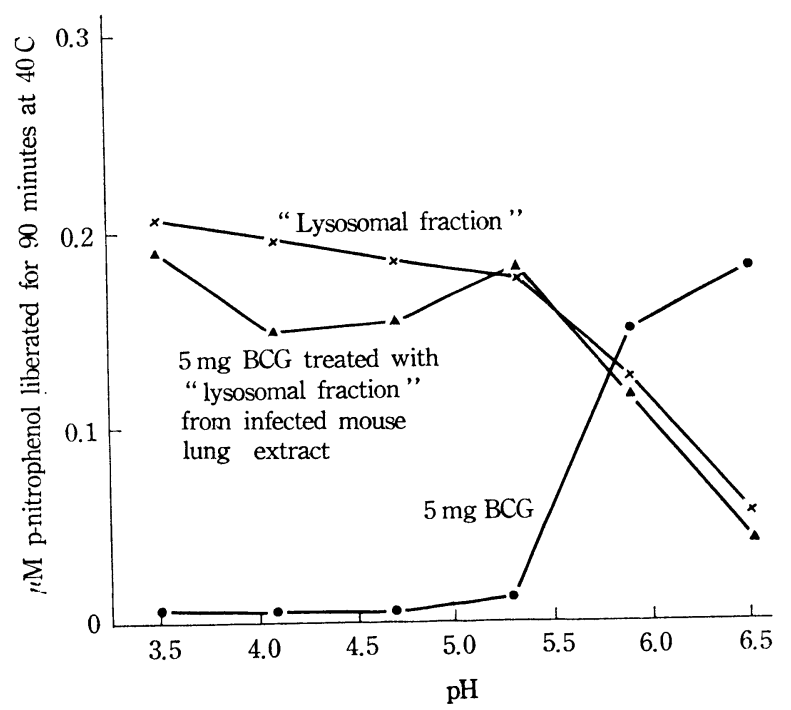

Fig. 12. Acid phosphatase activity of BCG treated with "lysosomal fraction " obtained from infected mouse lung homogenate, in comparison with original BCG grown on Sauton medium.

solution by the same centrifugal speed, each time dispersing the pellet by Teflon-grinder. Ziehl-Neelsen staining proved that the sediment consisted purely of acid-fast bacilli.

Acid phosphatase activity of BCG thus treated was examined as usual in comparison with untreated BCG. In this case, however, the enzyme reaction was conducted in the environment of $0.25 \mathrm{M}$ sucrose. The result is shown in Fig. 12. The pattern of $\mathrm{pH}$ 
activity curve of the treated BCG is almost the same as "lysosomal fraction". The low activity at $\mathrm{pH} 6.5$ is also a matter of interest, in view of the fact that the material was purely BCG organisms grown in vitro.

A carefully controlled experiment was added here to observe the effect of Triton $\mathrm{X}-100$ ( $5 \%$ in sucrose environment) on the enzyme activity of the treated BCG as above. The result is shown in Table 6, which indicates that per cent decrease of the activity was $46.4 \%$ which was much lower than that of "lysosomal fraction". These observations negate the possbility that acid phosphatase activity of BCG organisms treated with "lysosomal fraction" is due to simple contamination by the fraction. A more intimate interaction between the bacilli and the fraction is suggested. Fig. 13 is an example of the effect of incubation with "lysosomal fraction" derived from normal lungs. The fraction from the normal lungs was less active in this respect.

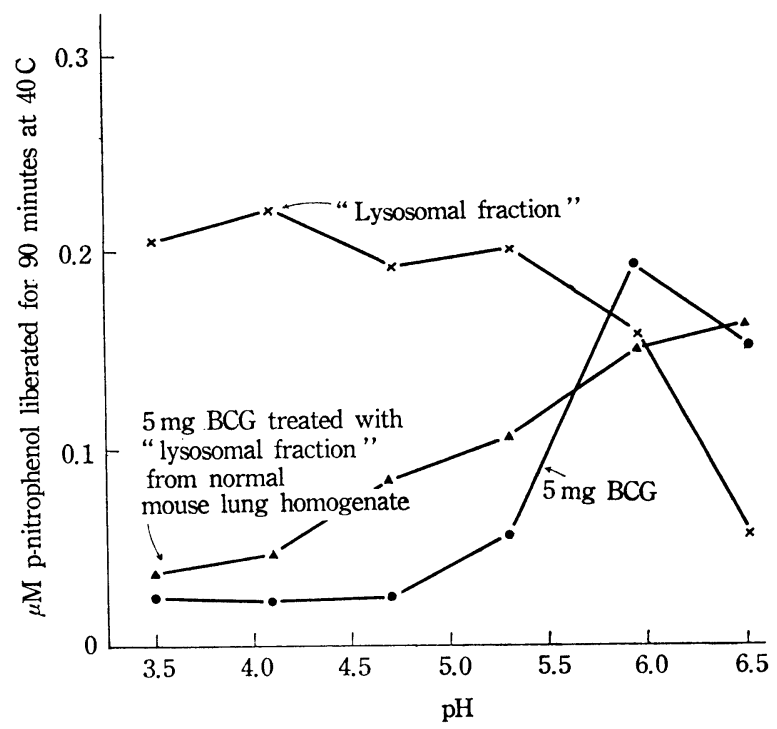

Fig. 13. Acid phosphatase activity of BCG treated with "lysosomal fraction " obtained from normal mouse lung homogenate, in comparison with the original BCG grown on Sauton medium.

Table 6. Effect of the treatment with Triton X-100 on acid phosphatase activity of "lysosomal fraction" obtained from infected mouse lung homogenate and of BCG incubated with the fraction

\begin{tabular}{cccc}
\hline \multirow{2}{*}{ Sample } & \multicolumn{2}{c}{ Specific activity* } & \multirow{2}{\%}{$\begin{array}{c}\text { Decrease } \\
\text { of activity }\end{array}$} \\
\cline { 2 - 3 } & Pretreatment & Posttreatment & 89.6 \\
\hline "Lysosomal fraction" & 3.75 & 0.39 & 46.4 \\
$\begin{array}{c}\text { BCG incubated with } \\
\text { the fraction }\end{array}$ & 1.55 & 0.83 & \\
\hline
\end{tabular}

* $\mu \mathrm{M}$ p-nitrophenol liberated at $40 \mathrm{C}$ in 120 minutes per $\mathrm{ml}$ suspension. The activity was measured in $0.1 \mathrm{M}$ acetate buffer $(\mathrm{pH} 4.1$ ) containing sucrose in $0.25 \mathrm{M}$. 


\section{DISCUSSION}

In association with native and acquired resistance to tuberculous infection, acid phosphatase activity of the host tissue has been attracting attention of several authors, particularly concerning the activity of macrophages and histiocytes (Grogg and Pearce, 1952) (Weiss and Fawcett, 1953) (Suter and Hulliger, 1960) (Thorbecke et al., 1961) (Allison et al., 1961) (Kanai, 1964) (Saito and Suter, 1965). Supporting the observations of these authors, the present study demonstrated that BCG-vaccinated mice responded to challenge infection with an accelerated elevation of the enzyme activity of the lungs. In order to explain this observation, the papers of North and Mackaness (1963 a, b) should be cited here. They studied on experimental mouse listeriosis as a model of infection with the intracellular parasite. Electronmicroscopical observation was done on the early cytoplasmic response of the periotneal macrophages to the presence of ingested bacteria in normal and immunized mice. They found the membrane fusion in the contact place between the lysosome and phagocytic vacuole and also a substance around the ingested bacteria which was the same in electron density as the lysosomal content. The only difference between normal and immunized mice in this respect was that such lysosomal response of the macrophages occurred and proceeded more rapidly in the latter. In addition to this observation, Horn et al. (1964) demonstrated histochemically the presence of acid phosphatase around ingested bacteria within phagocytic vacuole.

These informations provided the basic idea underlying the present investigation that in vivo grown tubercle bacilli might be associated with lysosomal components on their surface, for instance with acid phosphatase. Actually, the samples of such bacilli separated directly from the infected mouse lungs showed the host-type acid phosphatase activity, not of the original type of in vitro grown tubercle bacilli. Several evidences were presented to prove that this observation was not due to contamination of the samples by tissue components unassociated with the bacilli.

First, a simple mixture of in vitro grown tubercle bacilli and lung tissue homogenate showed a combined pattern of the enzyme activities of both materials and not of the H37RvL type. Secondly, the enzyme of the lung tissue homogenate is light enough to be removed by the differential centrifugation employed here for separation of H37RvL. Thirdly, the cytochemical staining of the H37RvL sample at $\mathrm{pH} 3.5$ could manifest black stained particles, and this did not occur in H37Rv. Fourthly, the comparison between the H37RvL sample and the infected lung homogenate from which the H37RvL sample was obtained, regarding the stained number of acid-fast bacilli and the enzyme activity, suggested that host acid phosphatase might be concentrated in association with bacillary bodies. Fifthly, the cell wall fraction separated from H37RvL still showed the pattern of host acid phosphatase activity. Sixthly, the model experiments to incubate in vitro grown tubercle bacilli with lung tissue extract or "lysosomal fraction" showed that the bacilli thus treated acquired the host-type acid phosphatase activity.

Thus, it will be concluded that acid phosphatase activity of in vitro grown tubercle bacilli is masked or lost during their stay in the mouse lungs, and that host acid phosphatase attached to the bacillary bodies. However, it is not known whether the host enzyme is located directly on the bacillary surface or indirectly on an intermediate presence of other lysosomal components. As will be reported in the succeeding paper, viability of $\mathrm{H} 37 \mathrm{RvL}$ bacilli has a much stronger resistance to $\mathrm{NaOH}$ treatment, by which the host-type acid phosphatase is abolished from H37RvL. This may suggest 
one possibility that some host substances are present directly on the surface of H37RvL bacilli which protect them from the effect of $\mathrm{NaOH}$, and that host acid phosphatase is located on such a protective layer. Another possibility would be that the H37RvL sample is a heterologous population consisting of the bacilli whose acid phosphatase activity is masked or abolished and of the secondary lysosomes which are essentially phagocytic vacuoles containing ingested tubercle bacilli and acid phosphatase given by the primary lysosomes.

Lung tissue extracts and "lysosome fractions" obtained from infected mice were more effective in conferring host-type acid phosphatase activity to in vitro grown bacilli by incubation at $37 \mathrm{C}$ than those derived from normal mice. The immunological specificity in this observation will be a matter of future research.

In the present experiments, the accelerated enzyme response was accompanied by the inhibition of multiplication of challenge strain. Despite this observation, however, there is no convincing evidence proving that host acid phosphatase is acting directly against tubercle bacilli to inhibit their multiplication or to destroy their structure. It is quite probable that some other lysosomal components are responsible for that. Recent studies of Zeya and Spitznagel (1966a, b) on lysosomal cationic proteins are most interesting in this respect. Because, the proteins were repopted to have an antibacterial activity. Lysozyme would also be worthy of renewed study in view of the observations of Thacore and Willett (1966). In any case, tubercle bacilli can multiply and survive long in the host as an intracellular parasite probably under the influence of lysosomal components. This situation will naturally produce an intimate association between the bacilli and lysosomal components. In fact, Merckx et al. (1964) have demonstrated by electronmicroscopic observation a particular structure designated as $\mathrm{X}$ body in the mouse lungs infected with $\mathrm{H} 37 \mathrm{Rv}$ tubercle bacilli, which they interpreted as being a result of interaction between tubercle bacilli and lysosomes. Taking together this and the findings reported in this paper, the present author believes that subcellular events of tuberculous infection are reflected on the biological properties of "in vivo grown tubercle bacilli".

\section{ACKNOWLEDGMENT}

Appreciation is expressed to Miss. Tamura for her helpful technical assistance.

\section{REFERENCES}

Allison, M. J., ZAPPASODI, P. AND LuRIE, M. B. (1962) : Metabolic studies on mononuclear cells from rabbits of varying genetic resistance to tuberculosis. Am. Rev. Resp. Diseases, 85, 364-370.

Artman, M. AND BeKIERkunst, A. (1961): Studies on Mycobacterium tuberculosis H37Rv grown in vivo. Am. Rev. Resp. Diseases, 83, 100-106.

GOMORI, G. (1941) : Cited from Histochimie et Cytochimie Animales. Principles et Méthodes, $3^{\circ}$ édition. Auteur Lucien Lison, 1960. Gauthier-Villars \& Co., Paris.

GrogG, E. AND Pearce, H. G. E. (1952): The enzymic and lipid histochemistry of experimental tuberculosis. Brit. J. Exptl. Pathol., 33, 567-576.

HIRSCH, J. G. (1962) : Cinemicrophotographic observations on granule lysis in polymorphonuclear leucocytes during phagocytosis. J. Exptl. Med., 116, 827-834.

Hirsch, J. G. (1965): Phagocytosis. Ann. Rev. Microbiol., 19, 339-350.

HoRn, R. G., SPICER, S. S. AND WeTzeL, B. K. (1964) : Phagocytosis of bacteria by heterophil leucocytes. Am. J. Pathol., 45, 327-335.

KANAI, K. (1964): Changes of acid phosphatase activity of the liver and the spleen in experi- 
mental mouse tuberculosis. Kekkaku, 39, 112-116. (Text in Japanese with English summary)

KANAI, K. (1964): Acid-phosphatase activity of mycobacteria. Kekkaku, 39, 149-154. (Text in Japanese with English summary)

KanaI, K., Wiegeshaus, E. AND SMITH, D. W. (1965): Detection of lipids of in vitro grown mycobacteria in bacilli separated from infected tissues. Report in Kolliquium im Forschungsinstitute Borstel über die Variabilität der Mykobakterien unter experimentellen und klinischen Bedingungen. Am. 13, 14 und 15. October 1965.

LOCKWOOD, W. R. AND Allison, F. (1963) : Electronmicrographic studies of phagocytic cells. I. Morphologic changes in the cytoplasm and granules of rabbit granulocytes associated with ingestion of rough pneumococci. Brit. J. Exptl. Pathol., 44, 593-600.

Merckx, J. J., Brown, A. L. AND KarLson, A. G. (1964): An electron-microscopic study of experimental infections with acid-fast bacilli. Am. Rev. Resp. Diseases, 89, 485-496.

NORTH, R. J. AND MACKANESS, G. B. (1963 a) : Electronmicroscopical observations on the peritoneal macrophages of normal mice and mice immunized with Listeria monocytogenes. I. Structure of normal macrophages and the early cytoplasmic response to the presence of ingested bacteria. Brit. J. Expt. Pathol., 44, 601-607.

NORTH, R. J. AND MACKANEss, G...B. (1963 b) : Electronmicroscopical observations on the peritoneal macrophages of normal mice and mice immunized with Listeria monocytogenes. II. Structure of macrophages from immune mice and early cytoplasmic response to the presence of ingested bacteria. Brit. J. Exptl. Pathol., 44, 608-611.

Rowley, D. (1962) : Phagocytosis. Adv. Immunol., 2, 241-264.

Segal, W. AND Bloch, H. (1956) : Biochemical differentiation of $M$. tuberculosis grown in vivo and in vitro. J. Bacteriol., 72, 132-141.

SuTER, E. AND HUlliger, L. (1960): Nonspecific and specific cellular reactions to infections. Ann. N. Y. Acad. Sci., 88, 1237-1245.

SAITO, K. AND SUTER, E. (1965) : Lysosomal acid hydrolases in mice infected with BCG. J. Exptl. Med., 121, 727-738.

ThaCORE, H. AND WilletT, H. P. (1966): The formation of spheroplasts of Mycobacterium tuberculosis in tissue culture cells. Am. Rev. Resp. Diseases, 93, 786-791.

Thorbecke, G. J., Old, L. J, Benacerraf, B. ANd Clarke, D. A. (1961) : A histochemical study of acid and alkaline phosphatase in normal livers during various conditions modifying activity of the reticuloendothelial system. J. Histochem. Cytochem., 9, 392-399.

WeIss, L. P. AND FAwCETT, D. W. (1953) : Cytochemical observations on chicken monocytes, macrophages and giant cells in tissue culture. J. Histochem. Cytochem., 1, 47-55.

YAmaGuCHI, J., ARIMICHI, F., FuKushi, K. AND OKA,, S. (1966) : Electronmicroscopical and cytochemical studies on the tubercle bacillus. Kekkaku, 41, 48. (Text in Japanese)

Yegian, D. AND VANDERLINDE, R. J. (1947): The nature of acid-fastness. J. Bacteriol., 54, 777-783.

ZEYA, H. I. AND SPITZNAGEL, J. K. (1966 a) : Cationic proteins of polymorphonuclear leucocyte lysosomes. I. Resolution of antibacterial and enzymatic activities. J. Bacteriol., 91, 750-754.

ZEYA, H. I. AND SPITZNAGEL, J. K. (1966 b) : Cationic proteins of polymorphonuclear leucocyte lysosomes. II. Composition, properties, and mechanism of antibacterial action. J. Bacteriol., 91, 755-762. 